\title{
El origen de una élite negociante en Madrid: los mercaderes de lonja franceses en el siglo XVII*
}

\author{
María Dolores Ramos Medina **
}

\begin{abstract}
RESUMEN
El objeto de este artículo es analizar las empresas francesas en

Madrid en el siglo xvil. En primer lugar, presentamos una aproximación a la tipología mercantil.

En segundo lugar, estudiamos la estructura empresarial que revela el afianzamiento del capital comercial galo en Madrid a través de una compleja red entre Madrid y los

diferentes lugares de Europa.

Finalmente, analizamos las redes comerciales y financieras que la burguesía mercantil francesa despliega desde Madrid.

ABSTRACT

The aim of this article is to analyse the french associative pacts within the commerce and finances throughout the 17th century in Madrid. First of all, this article tries to charaterize the social and economic group dedicated to trade and business in order to situate these merchands in the urban hierarchy in Madrid. Many of them were invested in many economic activities. Special attention is paid to the identification of French merchants active in the export of wool to Europe (in particular, France and Flanders) Some information is given about their economic wealth, and it is proved that they were much less rich than the members of the noble oligarchy in Madrid. Their negotiations and commercial activities were developped into the setting of a complex between Madrid and different places in Europe.
\end{abstract}

* Este trabajo forma parte de los proyectos de Investigación: DGIYT PB-96-097 y ESCOMARIN BHA 2000-0183-CO2-01.

** UNED (proferosa asociada) y becaria postdoctoral. Comunidad de Madrid. 


\section{INTRODUCCIÓN}

Durante el siglo xVII, los comerciantes franceses alcanzaron una considerable importancia numérica entre las colonias extranjeras en la vida española que contribuyó a que algunos mercaderes participasen activamente en la economía de la época ${ }^{1}$. En este periodo, se va perfilando, en Madrid, la imagen de un tipo humano dinámico que participa casi en exclusividad de las características señaladas a la corriente migratoria gala en el siglo XVII integrada por mano de obra no especializada, artesanos y un número insignificante de personas dedicadas a la actividad mercantil, medianos y pequeños comerciantes, muchos de ellos mercaderes ambulantes (también denominados mercaderes «caxeros") ${ }^{2}$, y casi ninguno de ellos con intención de establecerse definitivamente, pues la mayoría preferirán comerciar a distancia, confiando los géneros a terceras personas.

El contraste con los genoveses y flamencos afincados en Madrid es radical, puesto que tanto la colonia ligur, exclusivamente mercantil y carente del peso demográfico de la colonia gala, y la flamenca, con un mayor peso demográfico, pérmite ofrecer manifiestas diferencias económicas y sociales ${ }^{3}$. Tampoco vinieron financieros comparables a los banqueros genoveses o a los hombres de negocios portugueses. Incluso los grandes mercaderes fueron escasos, aunque varios de ellos obtuvieron naturalización para comerciar con Indias. En ello tal vez haya incidido que, a lo largo del siglo xvII, la historia de la inmigración francesa nos presenta el aleccionador espectáculo de un choque entre los factores políticos que tendian a elevar barreras entre ambos pueblos y los económicos que impelían irresistiblemente a los mercaderes franceses a establecerse aquí en busca de elevadas ganancias, o de simple subsistencia, añadiriamos nosotros. Choque en el que, a la postre, quedaron vencedores los protagonistas de aquella pacífica in-

Dominguez Ortiz, A. Los extranjeros en la vida española durante el siglo xvil. Sevilla, 1996, pp. 76 y ss.

2 Domínguez Ortiz, A. Los extranjeros (...), pp. 77 y ss.; Giralt y Raventos, E., “La coIonia mercantil (...)". Pp. 218 y 19.

3 Ramos Medina, M. ${ }^{2}$ D., "Mercaderes flamencos en Madrid: la Casa y Compañía Dupont (1650-1679)", Espacio, Tiempo y Forma. Serie IV, H. a Moderna, t. 13, 2000, pp. 221-249. Y en: La formación del capital comercial en Madrid en el siglo XVII: compañias mercantiles, mercaderes y hombres de negocios. (en prensa). 
vasión a los que medidas vejatorias, contribuciones y secuestros no consiguieron desanimar ${ }^{4}$.

Quizás, sea la razón del escaso interés que han generado estos mercaderes en el panorama madrileño, en particular, desde el punto de vista de la historia de la empresa, la perspectiva más moderna de la reciente historia económica. Algunos trabajos, como los de $\mathrm{D}$. Alcouffe ${ }^{5}$, A. Domínguez Ortiz ${ }^{6}, \mathrm{C}$. Larquie y D. Ozanam ${ }^{7}$, hacían referencia a la existencia de una importante colonia mercantil en Madrid a lo largo de la época moderna, pero sin llegar a desvelar suficientes datos sobre la actividad económica en manos de estos inmigrantes. No obstante, el estudio sobre las casas comerciales de los Clemente y, más tarde, de los Dupont que presentan un planteamiento integrador desde el cual se aborda el liderazgo de la burguesía madrileña cuando analizamos el mundo del comercio extranjero en el Madrid de Felipe IV y Carlos $1{ }^{8}$ nos ha permitido canalizar esta investigación hacia los estudios sobre el capital mercantil y financiero en la época moderna, que nos acercasen a las bases económicas de la actuación, en general, de aquella burguesía mercantil ${ }^{9} \mathrm{y}$, en particular, a las empresas de la burguesía mercantil francesa en el siglo XVII ${ }^{10}$.

4 Dominguez Ortiz, A. Los extranjeros (...). p. 75

5 Alcouffe, D., «Contribution à la connaissance des émigrés français de Madrid au XVIle siècle". Melanges de la Casa Velázquez. II (1966), pp. 179-197.

6 Domínguez Ortiz, A., «Guerra económica y comercio extranjero en el reinado de Felipe IV". Hispania. XXIII (1963), pp. 70-110.

7 VV.AA. Les français en Espagne à l'époque moderne (XVIe-XVIIle siècles). Paris, 1990.

8 Ramos Medina, M.a D., "Aproximación a la empresa artesano-mercantil francesa en la segunda mitad del siglo XVIt. Los mercaderes-fabricantes de peines de Madrid (1659-1679)",

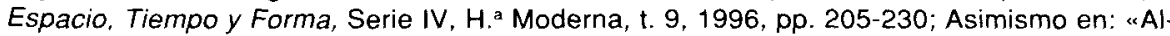
gunas sagas comerciales francesas en el Madrid de la segunda mitad del Seiscientos", Espacio, Tiempo y Forma, UNED, Serie IV, 12 (1999), pp. 223-247; “Mercaderes fiamencos (...)", pp. 221-249; Asimismo en: "Algunas compañias mercantiles francesas en el comercio minirista madrileño en la segunda mitad del Seiscientos". Cuaderno de Historia Moderna, U.C.M. 2001, núm.26, pp. 57-87.

9 Capella Martinez, M. y Matilla Tascón, A. Los cinco gremios mayores de Madrid. Estudio histórico-crítico. Madrid, 1957; Bravo LozANo, J., "Las posibilidades de Madrid a fines del siglo XVII. Francisco de Horcasitas». Estudios de Historia Social (1987), pp. 497-522; Alvar EzQuerra, A., "Mercaderes de Madrid (1540-1640), primeras notas", La burguesía española en la España Moderna. Valladolid, 1997, 3 vols, III, pp. 1439-1457.

10 Los estudios que hasta este momento se han realizado sobre el comercio francés en la peninsula en el siglo XVII han sido escasos y muy localizados. Algunos de ellos son: GiRARD, A. Le commerce français à Sevilla et Cadiz au temps des Habsbourg. París, 1932; Gómez ZoRRAQUINO, J.I. Zaragoza y el capital comercial. La burguesía mercantil en el Aragón 
En este sentido, este artículo enlaza con una valiosa línea historiográfica que tiene ya una larga tradición en la historiografía nacional, a partir de La Catalogne dans L'Espagne moderne de Pierre Vilar, cuya continuación, después de los trabajos dedicados hace medio siglo a algunas dinastías de hombres de negocios del siglo XVI (los Ruiz o los Espinosa), en las décadas de los ochenta y noventa el interés se dirigió hacia las burguesías del siglo XVIII. Como en otras cuestiones, los análisis sobre las burguesías del siglo XVII quedaron al margen de esta revitalización de la historia del comercio y de sus agentes.

Recientemente, la apuesta más decidida partió de un grupo de jóvenes historiadores, cuyos trabajos, abordan el estudio de la empresa seiscentista desde diversas perspectivas y desde diversas áreas geográficas. Debe citarse a Elisa Torres para Gran Canaria, Guadalupe Carrasco para Cádiz, Jeronia Pons para Mallorca y Juan Carlos Maixé Altés e Isabel Lobato para Cataluña. Estos estudios han facilitado el análisis de la empresa mercantil en el Madrid del siglo xVII y nos han suministrado el armazón necesario donde apoyar nuestra propia elaboración. De tal manera que, sin una base semejante el esfuerzo que hubiera exigido la delimitación del cuadro general del comercio extranjero en Madrid en el que se desenvuelve el proceso, que estudiamos, tal vez nos hubiera hecho desistir de la empresa ${ }^{11}$.

En este análisis, por tanto, adoptaremos como eje de su investigación el análisis estructural de la empresa francesa, señalando el diseño organizativo, el modo de funcionamiento, las características de su plan contable, la geografía de sus relaciones y el esquema evolutivo del negocio mercantil y financiero, dentro de la tarea más general de

de la segunda mitad del siglo xVII, Zaragoza, 1987, pp. 39 y ss.; GIRALT y RAventos, E., "La colonia mercantil francesa de Barcelona a mediados del siglo XVII', pp. 217-249; CARRASCO GONZALEZ, G. "Los mercaderes franceses en Sanlúcar de Barrameda. Una información sobre los privilegios de la nación francesa en el Sanlúcar del siglo XVIl». Actas del II Congreso de Historia de Andalucia. 1: Historia Moderna, Córdoba, 1991, pp. 381-388.

11 En este sentido, debe citarse a E. TORRES SANTANA. El comercio de las Canarias orientales en tiempos de Felipe III.Las Palmas, 1991; G. Carrasco. Los instrumentos del comercio colonial en el Cádiz del siglo XVII (1650-1700). Cádiz, 1997; J. C. MAIXÉ ALTÉs, Comercio y banca en la Cataluña del siglo xvm. La compañia Bensi y Merizano de BarceIona. 1724-1750. La Coruña, 1994; y, por último, I. LoBato Franco, Compañias y negocios en la Cataluña preindustrial, Sevilla, 1995 que realizan estudios de la empresa seiscentista desde diversas perspectivas y desde diversas áreas geográficas en la década de los novanta. 
definir la empresa comercial, tras conocer cómo surgió el mercader (empresario) que la dirigía y averiguar qué tipo de actividad realizó.

Además, la empresa comercial francesa en el siglo XVII se asoma a un nuevo período de esplendor. A partir de 1659, en opinión de $\mathrm{M}$. Zylberberg, se produce un cambio de papeles ${ }^{12}$, que podríamos interpretar, desde el punto de vista empresarial, como el comienzo de una nueva etapa para el capital francés en España. Es la ocasión aguardada con impaciencia desde hacía bastantes años, para que los comerciantes franceses intenten afianzar su situación económica en la Península ${ }^{13}$, garantizando así el aprovisionamiento de gran parte de los géneros que son demandados por los reinos españoles y sus territorios americanos. En el caso que nos ocupa, la localización de un documento que recoge la petición de juez conservador para la Corte en $1663^{14}$, en unos años en que se configura la primera institución económica de los gremios del Comercio de Madrid, nos hizo pensar en el alcance económico y social de la firma del Tratado de los Pirineos entre ambas Coronas que se traduce en un dinamismo comercial y financiero que reactivaría los negocios franceses en este periodo.

Con todo, una historia del comercio debe siempre tener presente entre sus objetivos, no sólo el análisis de la estructura también en nuestro trabajo, a pesar de conocer que en el horizonte del historiador del comercio deben aparecer objetivos tales como el volumen de los intercambios, el estudio de los vínculos que unen al tráfico con la producción y, por último, el destino de los capitales acumulados a partir de las actividades mercantiles, como hace algún tiempo advirtiera el profesor C.Martínez Shaw ${ }^{15}$, las dificultades no nos permiten nada más que dar una respuesta sesgada a la primera cuestión.

12 Zylberberg, M., Une si douce domination. Les milieux dáffaires français et l'Espagne vers 1780-1808, Paris, 1993.

13 Domínguez Ortiz, A., "España ante la paz de los Pirineos", Crisis y decadencia de la España de los Austrias, Barcelona, 1973, p. 157.

14 Según las fuentes de la época, la petición de juez conservador de la nación francesa para la Corte se argumentaba sobre el importante volumen de los negocios de estos mercaderes: Archivo(A.) Histórico(H) Nacional (N.), Consejos (C.), Leg. 7119, exp. 28, el 6 de septiembre de 1663. También en: Girard, A., Commerce française (...). p. 150; Pulido Bueno, 1., Almojarifazgo y comercio exterior en Andalucia durante la época mercantilista, 1526-1740. Huelva, 1993, p. 43.

15 Martinez Shaw, C., Cataluña en la Carrera de Indias, 1680-1756. Barcelona, 1981. 
En cuanto a las fuentes utilizadas, el presente estudio se ha realizado siempre a la luz del exámen minucioso de las numerosísimas minutas notariales, recopiladas entre casi un centenar de escribanías madrileñas. Un exhaustivo vaciado realizado que requirió de un laborioso trabajo de seguimiento de pistas en una heterogénea documentación notarial, constituida por más de 50 escrituras de poder o "procuras", 250 escrituras de compra-venta de mercancías (préstamos-obligación), así como los únicos quince testamentos y varios inventarios «post-mortem", que nos ha permitido ofrecer datos fiables sobre alguna de aquellas compañías. La ausencia de escrituras de creación, rescisión o renovación, de cuyos casos sólo tenemos noticias indirectas, nos permite descubrir la importancia de otro instrumento comercial y financiero apenas estudiado por la historiografía económica actual: las cuentas en participación, un modo de articular el capital comercial que no se registra en escritura alguna y del que conocemos su naturaleza a partir de documentación fragmentaria e indirecta que apenas deja rastro documental entre las minutas madrileñas. En realidad, se trata de una documentación dispar, pero que refleja, de forma indirecta, no sólo una prueba irrefutable de la importancia que tuvieron las empresas francesas sino también cómo la proliferación de estos órganos vitales de la microeconomía podrían ser un sintoma del desarrollo alcanzado y un índice de la eficacia del sistema de redes mercantiles y financieras.

\section{LOS MERCADERES DE LONJA FRANCESES ESTABLECIDOS EN MADRID. APROXIMACIÓN A UNA TIPOLOGÍA}

Tras el análisis de este reducido, pero muy activo, número de comerciantes que establecen la razón social de sus empresas en las calles más céntricas de la villa y cuyas relaciones económicas y sociales en el marco de la alianza entre el capital comercial y la especulación financiera encuentran en el parentesco una de las claves de su éxito, la trayectoria seguida por los comerciantes franceses de la primera generación que actúan en Madrid a mediados del Seiscientos, nos ofrece la perfilación sociológica que se descubre a través de las respuestas a cuestiones como hacia dónde orientan los capitales obtenidos de sus tráficos mercantiles, qué estrategias inversoras realizan y cómo van dando forma a sus patrimonios, avanza por estadios muy precisos pero siempre en un escalón inferior al de los negociantes esporádicos (loreneses, portugueses y flamencos). 
En este sentido, el comerciante francés en Madrid responde, en términos generales y no prescindiendo de su condición de fabricante ${ }^{16}, a$ la figura del comerciante polivalente, financiero y, en ocasiones, hasta arrendador y asentista, tal es el caso de Pierre Catalán, que en cierto modo augura la figura empresarial descrita por J. Savary en El parfait negociant en 1673 que se identificaba con la del comerciante para quien ningún terreno parecía estar vedado, equiparándose a aquella figura empresarial en promoción que asciende por los peldaños de la sociedad madrileña en un proceso de identificación con la burguesía mercantil autóctona de su mismo o similar nivel socio-profesional que se enmarca dentro de la más amplia problemática de buscar los orígenes del papel bancario de la Corte ${ }^{17}$.

Además, se ha de partir de la consideración de que, el término «mercader» francés en la época moderna, que no cabe duda encubría una realidad económica y social indeterminada, alude al arquetipo mercantil que define el típico temperamento de empresario, cuyo perfil sociológico abarca una amplia gama de posibilidades que va desde, quienes teniendo establecida casa de comercio, exponen en sus anaqueles géneros de la más variada indole y procedencia, hasta aquellos que añaden a sus tráficos los productos agropecuarios e intervienen en los mercados crediticios y de la propiedad inmobiliaria 18 encubriendo un conjunto de actividades económicas muy rico y complejo que no se encuentran exentas de riesgo y complejidad financiera por medio de elementos como el parentesco y la adscripción nacional y bajo la óptica de la vida cotidiana en los negocios, donde la endogamia de clase se imbrica con el ejercicio continuado de las actividades mercantiles. En unas ocasiones, como miembros de un sector específico burgués y comercial, los mercaderes franceses que se establecen en Madrid, siguiendo una tendencia migratoria antigua, lo

\footnotetext{
16 Ramos Medina, M. a D., "Aproximación (...)", pp. 205-225.

17 TEDDE, $P$., "Comerciantes y banqueros al final del Antiguo Régimen», Historia económica y pensamiento social. G. ANES, L.A., Rojo, P. TEDDE (eds.), Madrid, 1983, pp. 301 331; ZYLBERBERG, M., Une si douce domination. Les milieux d'affaires français et L'Espagne vers 1780-1808. París, 1993; STEIN, S.J., “Un raudal de oro y plata que corría sin cesar de España a Francia: Política mercantil española y el comercio con francia en la época de Carlos II'", Actas del Congreso Internacional de Carios III y la IIustración, Madrid, 1989, II, pp.

18 Archivo General de Simancas (A.G. S.), Contaduria del Sueldo (C.S.), 2. ${ }^{a}$ época, leg.
} 219-280. 149. 
hacen con un bagaje mercantil aprendido en contacto con la realidad económica europea.

Asimismo, al amparo de las claúsulas comerciales del Tratado de Paz, los mercaderes franceses recuperaron la libertad de acción y continuaron un comercio activo con su metrópoli considerado ruinoso por algunos portavoces de los intereses gremiales, industriales y mercantiles autóctonos de la Corte y venía a significar, entre otras cosas, la reapertura de un valioso mercado cerrado durante mucho tiempo a sus productos y a sus mercaderes, aunque gracias al contrabando practicado y otras medidas (naturalizaciones, sobre todo) dicho tráfico no había liegado a interrumpirse por completo. El tratado de los Pirineos (1659), además convierte al capitalista francés en un intermediario comercial y financiero al servicio de los grandes comerciantes franceses afincados fuera de la Península (tal es el caso de los Dugas de Saint-Chaumont (Lyon), los Chelot de París y los Vignaux de Olorón de Saint Marie) de comerciantes genoveses, portugueses, flamencos y holandeses, así como de financieros de la Corona.

No obstante, las acciones bélicas de Luis XIV contra los Países Bajos iniciadas en 1667 y que con carácter intermitente truncarán el proceso de paz, continuadas entre 1674 y 1679 y que se prolongan hasta finales del Seiscientos, la política agresiva de Luis XIV y las represalias con que responde España perjudicaron al apacible comercio de los franceses establecidos en Madrid. Esta situación exige la puesta a punto de un sistema sencillo que atendiera las complejas necesidades de una empresa comercial en crecimiento en un periodo de gran conflictividad cuando todavía el capital comercial francés no es dominante ${ }^{19}$. Más adelante, la acumulación de capital comercial al resguardo del crecimiento económico de la Corte del que es directamente beneficiaria la elite negociante extranjera, devuelve un dinamismo a los negocios franceses que hasta entonces en pocas ocasiones habian disfrutado ${ }^{20}$.

19 ISRAel, J. The Dutch Republic and the Hispanic World 1606-1661. Oxford, 1982, pp. 233 y 234.

20 A.H.N., Estado, Leg. 2810 , exp. 2 y 3. Tratados de paces originales entre Francia y España; GiRARD, A., Le commerce francaise à Seville et Cadix au temps des Habsbourg. París, 1932. Este estudio explicó ya largamente las ventajas inmediatas reportadas a Francia por las claúsulas comerciales de la Paz de los Pirineos. 
Sabemos que, a lo largo del siglo XVII, algunas familias cuya actividad era ya notable antes de 1630 , asientan su posición como agentes económicos en la práctica del comercio a la gruesa. El deseo de ganancia que presidirá sus actuaciones, tanto públicas (en el marco comercial madrileño y ante las instituciones económicas) como privadas lo que les impulsa a establecerse en las calles más comerciales de la Corte su residencia, y luego su carácter emprendedor como el aumento de su potencialidad económica resultante que, en ocasiones, queda truncada les conduce a desarrollar una actividad económica de altura. Destacan entre ellos los negociantes Blas Pichón, Guillermo Laurisecha y Daniel Sabola, mercader de lonja ${ }^{21}$. El primero llegó a ser «obligado del carbón", aunque su primer oficio fue el de tabernero de corte. Laurisecha, cuya trayectoria puede seguirse desde 1633 hasta 1657, desarrolló una importante actividad financiera colaborando con negociantes y banqueros de la Corte. Se trata de un modesto mercader que comercializa su producción en tienda, grupo al que pertenece también, en una primera fase, algunos mercaderes avecindados en la Corte y que en calidad de asalariados del capitalista madrileño participan en el abastecimiento de mercancías nacionales a la Corte.

La entrada de Francia en la Guerra de los Treinta Años significa un duro golpe para los intereses galos en Madrid. Numerosos mercaderes deben huir para escapar de las represalías y prohibiciones de comercio ordenadas en 1635, regresando a sus lugares de origen y sólo algunos se quedan ${ }^{22}$. Conocemos varios casos, como el de Arnaldo Sapiençia, de origen francés y vecino de Madrid, que asume las funciones de administrador (corresponsal) de los negocios de algunas firmas parisinas hasta que, en 1638, decide trasladar sus negocios a la capital france$\mathrm{sa}^{23}$. Los lazos que unen a este mercader galo a Juan Bartherot, joyero francés, afincados en Madrid a principios del siglo XVII, se observan en las relaciones comerciales que establecen entonces cuando Juan Bartherot se encarga de la comercialización de mercancías manufacturadas que pertenecen a Sapiençia que, desde París, sigue manteniendo una fluida correspondencia con Madrid. En este caso, el

${ }^{21}$ A.G.S., Contaduria Mayor de Cuentas (C.M.C). 3. a época, Leg. 422 y en Archivo Histórico de Protocolos de Madrid (A.H.P.M.), Protocolo (P. ${ }^{\circ}$ ) 5875, fols. 168-232. Inventario de los bienes de Daniel Sabola, mercader de lonja francés.

22 Sanchez Belén, J.A., y Ramos Medina, M. ${ }^{a}$ D., "Los comerciantes franceses en Castilla y la represalia de 1667”. Espacio, Tiempo y Forma. I, 7 (1994), pp. 287-318.

23 A.G.S., C.S., 3. ${ }^{a}$ época, Leg. 422. 
papel de ciudad proveedora de mercancías manufacturadas se observa en sus relaciones con los mercaderes de casas comerciales como Gisberto Chelot, mercader de París, y Francisco Legrand, hombre de negocios y pater familias de la casa comercial en París, que se convierte, hasta 1655 , en proveedor de quincalla y mercería de la lonja Bartherot en Madrid ${ }^{24}$. Gisberto Chelot es corresponsal, en Madrid, de su hermano Carlos, en París, en negocios en cobros, en concepto de comisión, a Román Grifón, un mercader de lonja francés, en 1660. Este asunto parece que no queda concluido a la muerte de Grifón, en 1667, siendo Carlos Chelot, administrador societario y, posiblemente, socio (capitalista) quien envíe a su hermano Gisberto a Madrid para que represente a la firma parisina en el pleito contra los herederos de Román Grifón, por unas cantidades que adeuda el mercader galo a los Chelot por las comisiones generadas en la venta de mercancias.

Por tanto, habrá que esperar a los años posteriores a la firma de la paz de los Pirineos (1659) para que, entre la nómina de mercaderes franceses que actúan en Madrid, aparezcan algunos comerciantes al por mayor y hombres de negocios relevantes. De ellos, sólo unos pocos se incorporan al grupo de grandes comerciantes y que consiguen introducirse en el comercio americano, tal es el caso de Simón Salet y Pedro Catalán ${ }^{25}$.

Por otra parte, entre los merceros y joyeros franceses que más destaca la documentación notarial encontramos a Juan Bartherot y a Román Grifón. Los datos personales sobre estos personajes son muy escasos. Ambos mercaderes llegan a la Corte a finales de los años veinte y durante la década de los treinta comienzan su carrera profesional en las lonjas de parientes y amigos. La trayectoria mercantil y social de Juan Bartherot y Román Grifón es paradigmática de la que siguen los mercaderes franceses de la primera generación de empresarios franceses a la que representan. Hasta 1650, trabajan para mercaderes gestionando los negocios de la compañia familiar desde su sede social en el barrio de San Ginés y San Luis de la Corte. En 1652, tras explorar las inmensas posibilidades del comercio en Madrid, ambos mercaderes de lonja trasladan sus negocios a las calles Preciados y de

24 A.H.P.M., P. ${ }^{\circ} 10.099$, fols. 1-1v.

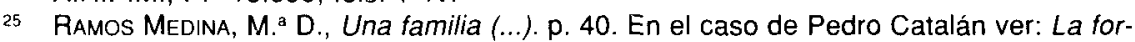
mación (...) (en prerısa). 
la Zarza, respectivamente, en los aledaños de la Puerta del Sol. Con seguridad, desde 1655 ejercen de mercaderes de lonja por cuenta propia y en colaboración con algunas firmas francesas afincadas en París, manteniendo una serie de relaciones plurivalentes en el mundo del tráfico mercantil y financiero y llegando incluso a estar presentes en las primeras experiencias atlánticas de la colonia extranjera en Cádiz.

La estancia en Madrid de esta primera generación afianza la posición de los mercaderes franceses, que considerados económica y socialmente como familias de relevancia, articulan un entramado interesante de relaciones de parentesco y amistad, no sólo en el seno de la comunidad francesa, sino también entre la burguesía mercantil y la sociedad madrileña de la época que permite aprovechar las oportunidades que la economía madrileña les ofrece. En efecto, la documentación notarial consultada recoge en estos términos la actuación de los mercaderes de lonja franceses, permitiéndonos hablar de una actuación conjunta presidida en cada momento por el cabeza de familia, que se encarga de la administración de los bienes y el negocio hasta que, en 1660 y 1667, respectivamente, se disgregue el capital comercial en manos de la segunda generación, la de los hijos de Juan Bartherot y los herederos de Román Grifón, entre los que se encuentran sus sobrinos Bartolomé y Blas Grifón.

Por supuesto, en esta trayectoria algunos individuos desaparecen antes de alcanzar el final, pero son los que establecen las bases de su evolución. Así, el fallecimiento de Juan Bartherot y Román Grifón, en 1660 y 1667, respectivamente, da paso a la segunda generación, la de los hijos y sobrinos de estos mercaderes de lonja que inician su actividad comercial siendo socios-factores de una compañía de la que se emancipan para formar la suya, dentro de un gremio comercial de Madrid, y en el caso de Pedro Catalán para acabar alcanzando la categoría de agente libre frente al agremiado, que se homologa a la burguesía mercantil madrileña. Por esta razón, las relaciones familiares entre los franceses no revistieron la importancia que tenían para la sociedad autóctona. No tuvieron, tampoco, las características de clan cerrado que caracterizó a los genoveses. Pero no dejaron de hacerse sentir. Además, la permanencia en Madrid, les fue incorporando activamente a la sociedad madrileña, llegando alguno de ellos a obtener el rango de asentista de la Corona (tal es el caso de Pedro Catalán, en 1662) e integrándose en esa elite urbana de buenos ciudadanos que residen en villas, ya sean funcionarios del rey, grandes comerciantes o gentes que viven de sus rentas constituyendo una pequeña burguesía 
mercantil que no sólo se especializa en el comercio en tienda y lonja también en las empresas de servicios comerciales y financieros ${ }^{26}$.

Los vínculos de las familias francesas adscritas a diversas casas comerciales extranjeras que se encuentran constituidas no sólo por todos y cada uno de aquellos individuos que compartiendo o no el mismo techo se encuentran unidos por estos lazos de sangre a los que nos referíamos en el caso de la casa Clemente, podían ser de varias clases, según tuvieran sus raíces en la tierra de origen o en la adoptiva. Una forma de establecerse en territorio extraño es la de recurrir al contacto y a la compañía de los compatriotas ya afincados ${ }^{27}$, a cuyo lado se aminora la añoranza del hogar paterno. Mediante cofradías y otras formas de asociación, se obtenían ventajas y socorros mutuos que aligeraban las molestias de la inadaptación inicial.

Las consecuencias de estos contactos podían sobrepasar el terreno de la ayuda circunstancial para adentrarse en la vida íntima y familiar de los franceses recién llegados y llevarlos al matrimonio con las hijas de franceses, nacidas en nuestros reinos. Este nuevo vínculo familiar evitaba la dureza del choque en tierra extraña y favorecía paulatinamente su asimilación y adaptación. De este tipo de uniones matrimoniales se encuentran varios ejemplos en la documentación utilizada. Así el francés Román Grifón, mercero, casó con la hija de su compatriota Juan de Hiche, tabernero de corte, establecido en Madrid desde principios de siglo. Pero la posibilidad de matrimonio para los inmigrantes no se agotaba con las hijas de los compatriotas sino que podía extenderse hasta las hijas de naturales. Las relaciones profesionales, el trato comercial era el camino para ello. Pero, en general, el matrimonio de estos mercaderes no se realizaba con elementos destacados de la sociedad mercantil madrileña, sino con hijas de artesanos o comerciantes tenderos.

Las relaciones familiares unieron a varios negociantes franceses con miembros de otras colonias de extranjeros. Juan Barranquet, oriundo de Bearne, contrajo matrimonio con la viuda de un mercader lorenés. Las

26 Al contrario de lo que sucede con otras colonias comerciales francesas, tal es el caso de los franceses en Zaragoza que, dedicados al negocio de importación y exportación, no se preocupan por otra serie de actividades más lucrativas: GomEZ ZORRAQUINO, J.I. Zaragoza y el capital comercial. La burguesia mercantii en el Aragón dela segunda mitad del siglo xvil. Zaragoza, 1987 , pp. 39-43.

27 Piamos Medina, M. ${ }^{a}$ D., «Algunas compañías (...)», pp. 60 y ss. 
familias, además podian tener sus raíces hendidas en el territorio de origen en vez de ser el resultado de una larga permanencia en Madrid. En efecto, fueron muchos los franceses que llegaron a la Corte durante el siglo XVII teniendo ya un pariente inmigrado desde años atrás, como los Jolivet. El pater familias es el eslabón que atrae a los miembros de una misma familia, atraídos por los altos sueldos y por la facilidad del negocio. Así, la presencia en Madrid de Carlos Jolivet, desde mediados de siglo, explica la de su hermano Sebastián y su cuñada Margarita Muller, en 1663; como también la actividad y larga permanencia de Román Grifón, explica la visita de su sobrino Bartolomé, en 1649. De modo similar debe explicarse la presencia simultánea en Madrid de los hermanos Vignaux, padre e hijo, hasta 1662; o la de los hermanos Chelot, hasta 1670 , cuya relación de parentesco muestra el carácter familiar que para ellos revistió la inmigración. Al mismo tiempo, estos mercaderes, a la vez que afianzan su posición económica en el mundo del comercio a la gruesa, la comisión y los cambios, consolidan la posición social de su familia, entrando a formar parte, con el tiempo, de una de esas familias burguesas gracias a una política matrimonial fuertemente constreñida al sector del patriciado urbano, con el que, en ocasiones, comparten unos orígenes comunes.

Otro tipo de relación que constituye como un apendice de la relación familiar, era la doméstica. Efectivamente, eran varios los franceses que se hallaban empleados en los negocios de sus compatriotas establecidos desde tiempo en Madrid. Es el caso de Juan de la Tapié y Bartolomé Grifón, empleados respectivos de Bernardo Peberán, peinero francés, y Román Grifón, mercader de lonja francés, aposentados en la misma casa del dueño, formando parte de la familia, según era costumbre entonces entre los aprendices, oficiales de artesanos y mercaderes. Unos habían sido contratados accidentalmente en la ciudad, y otros, por fin llegarían a ella recomendados por sus paisanos al compatriota que, por su tiempo de residencia o por la importancia de sus empresas, podía adiestrar al recién llegado en el trabajo mercantil e iniciarlo en los negocios. Existía también entre franceses la pura y simple relación del dueño al criado, como la mantenida por el tendero Román Grifón con Juan Folat, el cual vendía mercería a cuenta y riesgo del primero por las calles de Madrid. Hasta 1660, ambos mercaderes de lonja franceses permanecen en Madrid en representación de los intereses de las firmas extranjeras para la comercialización de las manufacturas europeas expedidas desde Francia en dirección a la Corte, y en el mundo de los cambios 
y las comisiones, siendo el parentesco y las relaciones sociales que establecen la clave de su éxito.

Durante los primeros años, la actividad de unos y otros parece haber sido prioritaria, apareciendo en solitario durante ellos hasta que ambos contraen matrimonio con hijas de mercaderes matriculados pertenecientes a familias de origen francés haciendo la doble salvedad de la imposibilidad de reconstruir la historia de sus familias por la falta de documentación y el especial hincapié que hemos hecho en los miembros pertenecientes a las dos generaciones que estamos analizando. El primero contraía matrimonio con Maria de Cabrera, hija de un tabernero de corte en 1634. Mientras que Román Grifón contraía matrimonio con María Hiche, hija de un pastelero francés, afincado en Madrid a principios de siglo. En ambos casos, a mediados de siglo eran dos reputados mercaderes de lonja que traficaban en el comercio de importación y exportación en nombre de los comerciantes franceses de París. En este sentido, localizamos al comerciante que en las primeras décadas del siglo XVII ha consolidado su posición económica. Se podría identificar con Daniel Sabola, mercader de lonja francés que fallece en 1633 y con Juan Bartherot, a quien la muerte sorprende en 1660 . Su estatus socioeconómico define a un comerciante importador en géneros de tienda, pero que no duda en realizar tímidas incursiones en el mercado crediticio y otras más considerables en el de la propiedad inmobiliaria, que adquiere una relativa importancia en un mercado como el madrileño en constante revalorización.

En otras ocasiones, el mercader (capitalista), que abarca desde el pequeño comerciante que cuenta con un capital inicial, pasando por el mercader-fabricante de productos sunturarios tan demandados en la Corte, hasta el comerciante internacional, forma compañias con otros mercaderes de su mismo ramo profesional -tal es el caso de los joyeros, merceros y especieros analizados- y que incorporan a mancebos y criados a sus instalaciones comerciales en Madrid. A este grupo se unen otros capitalistas que aportan dinero y modestas infraestructuras a mercaderes (capitalistas) alejados del comercio al detaIle. De manera análoga a lo observable en la sociedad madrileña, los vínculos familiares se entrelazaban con las actividades profesionales entre los franceses. El citado Baraduque era consocio de su suegro, en compañía del cual explotaba una tienda de joyería, cuyas mercancías, en gran parte, eran suministradas por los familiares de Baraduque en la capital francesa. Es evidente, pues, que la relación familiar 
sirvió de soporte a muchas actividades comerciales desarrolladas por los inmigrantes franceses. Esta colaboración mercantil trascendía, no obstante, el ámbito familiar para extenderse a otros miembros de la colonia respecto a los cuales se descubren actos de solidaridad y endogamia socio-profesional.

Con este panorama la burguesía mercantil francesa en Madrid aprovecha esa coyuntura dificil, ya que el riesgo de confiscaciones y prohibiciones, así como la naturaleza socioeconómica de esta inmigración, favorece que los franceses que se establecieron en Madrid no tengan una actividad específica ${ }^{28}$. Del mismo modo, la paz de los Pirineos convierte al capitalista francés en un intermediario comercial y financiero al servicio de los grandes comerciantes franceses afincados fuera de la Península ( tal es el caso de los Dugas de Lyon, los Chelot de París y los Vignaux de Olorón de Saint Marie) asi como de mercaderes de lonja genoveses, portugueses y holandeses y, por último, de financieros y banqueros de la Corona que no disponen de infraestructura material en las redes del comercio atlántico cuando las posiciones perdidas en el ámbito comercial peninsular y colonial pronto sean recuperadas, afianzándose desde entonces gracias al trato de nación más favorecida.

Por último, la asimilación y proceso social hace referencia a los numerosos matrimonios contraidos por los franceses inmigrantes con mujeres naturales de Madrid o con las hijas de los inmigrados, nacidas en territorio español. Por medio de estos enlaces la asimilación fue rápida. En primer lugar, la actividad mercantil y una posición económica independiente les distanciaba de los demás franceses que nutrian los más ínfimos peldaños del artesanado y el comercio, así como de los hombres de fortuna y los que no tenían más recursos que el jornal. Una vez conseguido este capital inicial el camino del ascenso social era mucho más fácil. Pero, en ocasiones, el apellido de estas sagas desaparece, fenómeno que tiene lugar en la generación cuya actuación transcurre entre 1660 y 1679, acentuándose el carácter de yernocracia, debido a que la debilidad demográfica de la familia no permitió la continuidad del negocio en manos del mercader.

28 La misma naturaleza económica se desprende de otros estudios sobre el capital comercial francés: GIRALT, E., “La colonia mercantil (...), pp. 217 y ss. Asimismo, en Zaragoza: Gómez Zorfaquino, J.I.. Zaragoza y el capital comercial. Zaragoza, 1987, pp. 39-43. 
Desde 1660, Juan Barranquet, Juan Dufao, Pedro Catalán, Juan de la Tapié y Juan Casanova pertenecen a la segunda generación de hombres de empresa, que proceden de escritorios de fabricantes franceses y evolucionan por los estadios de la negociación comercial y financiera completando la definición de la burguesía mercantil gala en Madrid, afianzando las posiciones del comerciante francés perdidas en el ámbito comercial madrileño en 1635, recuperando una actividad comercial y financiera, gracias al trato de nación más favorecida. De esta manera, el arranque de un proceso que responde al auge de los intercambios, en general, a partir de 1659 llevó a algunos hombres de negocios franceses a retener entre sus manos no sólo un importante negocio de redistribución también de servicios comerciales y financieros. Esta nueva etapa de relaciones comerciales entre la economía peninsular y el comercio francés venía a significar, entre otras cosas, la reapertura de un valioso mercado, cerrado durante mucho tiempo a sus productos y a sus mercaderes.

Aunque desconocemos las razones que influyeron en el negocio de Juan Barranquet a partir de 1652 para que tras haber comerciado con mercancías manufacturadas francesas en compañía con Bernardo Mercadet, un comerciante con importantes contactos entre los fabricantes de peines de la Puerta del Sol, decide articular su capital en solitario en cuentas en participación tras haber sufrido un proceso de contrabando por la ocultación de nueve fardos de peines en 1651. Quizás el riesgo que se corría en el comercio internacional y su matrimonio de conveniencia con María Guissén, una rica viuda de origen lorenés, permitió reorientar su negocio hacia la especulación comercial, añadiendo a los productos de su mercería de la calie de las Postas, la exportación de lanas y especias a la par que ampliar las bases de los mercados de capitales, bienes raíces e inmuebles urbanos trasladando su negocio a la sede social de la empresa de su esposa. En este sentido, el papel de los parientes, en un grado u otro, adquiere una gran importancia porque, unas veces, favorece el ascenso social del linaje como, en otras, la continuidad de los negocios a la segunda generación que traslada a otros centros económicos donde desarrolla un trabajo de comisionista, optando por un ascenso más social que económico, tal es el caso de Bartolomé Grifón, sobrino de Román o Pedro Furiel, yerno de Juan Bartherot proporcionando nuevas oportunidades de crecimiento económico en el seno familiar aunque con connotaciones propias. 
Para Juan de la Tapié y Juan de Casanova, por ejemplo, tras haber aprendido el oficio en el escritorio de fabricantes de parientes y amigos en Bayona, Pamplona y Madrid, el ejercicio de administrador de la compañía con Bernardo Peberán (en el caso de Juan de la Tapié) y con Guillermo Forcada (en el caso de Juan de Casanova) en el negocio y fábrica de peines, tratos de mercancías, cambios y encomiendas entre Francia y España que tendría una vigencia de casi diez años, desde 1659 hasta 1669, les permitirá adquirir el capital suficiente para emprender su carrera profesional en solitario en la década de los setenta y los ochenta.

Por último, la actividad de otros comerciantes franceses se ha consolidado en el abastecimiento de mercancías de procedencia europea con un determinado enclave geográfico exterior donde disponen, al menos de una unidad operativa administrada por el pater familias de la compañia en Madrid. Tal es el caso de los Cortada de Thiers, así como de los Jolivet de París. Unos y otros, como élite comercial alejada de la etiqueta gremial, que caracteriza a otros mercaderes, se han pasado al ejercicio del gran comercio y la especulación que nace de la práctica comercial del siglo XVII, figura un grupo reducido de mercaderes de lonja, formados en los ambientes de los gremios de fabricantes de la Corte.

En suma, ambas generaciones de mercaderes, a la vez que se afianzan en el mundo del comercio a la gruesa, la comisión y los cambios, consolidan la posición social de la familia, entrando a formar parte, con el tiempo, de algunas de esas familias burguesas gracias a la política matrimonial fuertemente constreñida al sector del patriciado urbano, con el que, en ocasiones, comparten unos orígenes comunes. Con todo, observamos, que el comerciante francés de estos escritorios de comercio, actuando de enlace entre la economía gremial y la capitalista, no sólo auna dos conceptos, comercio al detall y al mayor, sino que también participa en las actividades típicas de la burguesía mercantil madrileña, invirtiendo el capital acumulado de la comercialización en una amplia gama de productos, asociado en compañía con otros mercaderes peineros, así como con merceros, joyeros o especieros con tienda abierta en los aledaños de la Puerta del Sol y calle Mayor, para más tarde convertirse en un verdadero hombre de negocios e introducirse en las redes del gran comercio madrileño con Europa y América, adquiriendo los medios necesarios que le permiten mejorar su posición social. De este modo, el comercio en «lonja» o al por mayor y el comercio en tienda o "vareado" conviven en armonía. 


\section{LAS EMPRESAS COMERCIALES DE LA BURGUESIAA MERCANTIL FRANCESA EN MADRID. CARACTERISTICAS Y ORGANIZACIÓN}

Después de esta caracterización, el análisis pormenorizado de los mercaderes franceses que acaban por instalar la cabecera de su negocio desde su solar de origen hasta la capital de la Monarquía Hispánica a lo largo del siglo XVI nos pone en contacto con una realidad empresarial desconocida hasta ahora: el caso de las empresas comerciales de la burguesía mercantil francesa en Madrid. En primer lugar, tenemos que adelantar que, en rigor, no se puede hablar de "empresa" comercial francesa como lo hemos entendido hasta ahora, pues en estos niveles tan elementales de la negociación las ausencias son más significativas que las presencias. Por una parte, carecen de conceptos globalizantes tales como casa comercial, reservados a las familias importantes y consideradas socialmente ${ }^{29}$, de tal modo que cuando hablamos de "empresas" nos referimos a sus actividades y negocios. Mientras tanto, en estos niveles tan elementales de la negociación tan sólo podemos hablar de "empresa comercial» cuando la estructura organizativa venga apuntalada por la compañía mercantil ${ }^{30}$.

La empresa gala, como lonja abierta, se desarrolla y evoluciona en los márgenes de los gremios del comercio de Madrid, en particular, del gremio de la Especiería de la calle de las Postas y Portal de santa Cruz, al que solamente se encuentran adscritos algunos mercaderesfabricantes de peines y algunos mercaderes ambulantes (los populares caxeros franceses). Durante el siglo XVil, la mayoría de los comerciantes franceses en Madrid, sin gremio propio y, por tanto, sin una corporación coordinadora de su actividad en Madrid, se sitúan en un espacio creado gracias al vacío legal en materia comercial, al no estar regulada su actividad comercial y financiera. Esta situación, además, perjudicaba a la Corona, pues mientras los comerciantes franceses estuvieran agrupados en el gremio de la Especiería, los beneficios fiscales que se derivasen de su actividad serían muy inferiores a los que se hubieran recaudado de estar agrupados en este gremio.

29 Ver Ramos Medina, M. ${ }^{a}$ D., Una familia (...), pp. 55 y ss.

3o Ver Ramos MedinA, M. ${ }^{a}$ D., "Aproximación (...)", pp. 205-230. Y en «Algunas compañías (...)*, pp. 61 y ss. 
Desde un punto de vista organizativo, la lonja francesa estaba dirigida por el propio mercader que era el encargado de gestionar los asuntos de la misma a través del escritorio de comercio como unidad básica de comercialización tanto al detall como al por mayor. La organización de algunos negocios requiere de un administrador, como representante legal de los intereses de la empresa en Madrid, que firme contratos de arrendamiento, escrituras de asientos con mancebos y vendedores a la vez que otorgue poderes a corresponsales en otras ciudades donde la compañía tenía intereses económicos. Este agente comercial atiende los negocios, tanto por cuenta propia como ajena, a través de su lonja-almacen en Madrid y desde alli actúa de gestor de los procesos de información adecuados tanto en su estructura interna (plan contable) como externa (corresponsalía).

No obstante, como empresas dedicadas a la distribución puede recibir mercancias en sus lonjas, pudiendo ofrecer, además, una segura información del estado de los mercados, de los precios de venta y de los productos, y puede facilitar a bajo precio su venta en otros lugares. En estas condiciones, el mercader francés ejerce de corresponsal permanente de las firmas francesas, genovesas y flamencas y puede ofrecer mejores servicios y ganancias por el hecho de no tener que vender las mercancías con urgencia, pudiendo retener la mercancía durante cierto tiempo en espera de mejores condiciones de mercado.

En cuanto a la gestión, las empresas mercantiles francesas localizadas participan de los rasgos comunes tanto de las sociedades colectivas (es decir, aquellas que disponen de una administración conjunta que obliga a todos los socios a mantener entre sí una fluida correspondencia, dando cuenta cada uno de su gestión después de haber concluido su negocio) como de las empresas comanditarias (como administador de cad auna de las parcelas de la actividad de la empresa ${ }^{31}$ ) en contacto con la realidad económica madrileña. Su peculiaridad radica en que con frecuencia no resulta imprescindible recurrir al escribano para concertar este convenio asociativo puesto que en el seno familiar el pater familias organiza el capital de la firma. Las dependencias que mantienen estas compañías con las casas comerciales francesas en París, Bayona y Lyon, así como con las flamencas (Marines-Truyens, por ejemplo) en Amberes, tras la paz de Wetsfalia, desde 1648, y tras la

31 Lobato Franco, I., Compañias y negocios (...), pp. 122-123. 
paz de los Pirineos, desde 1659, convierte a estos mercaderes de lonja en agentes comerciales (comisionistas) de las compañías extranjeras en Madrid.

Mientras tanto el instrumento comercial, por excelencia, es la cuenta en participación hasta que la compañía adquiera toda su relevancia en el siglo XVIII. En efecto, la articulación de ambas unidades organizativas no pueden comprenderse desde una visión unitaria sino analizamos unos convenios asociativos que se articulan en torno a una estructura compleja ${ }^{32}$. El eje de vertebración para que las familias comerciales, que protagonizan este estudio, sean analizadas desde una visión unitaria en el conocimiento de su estructura económica, alude a la localización de noticias dispersas y fragmentarias de unos convenios asociativos de naturaleza que no tienen trascendencia pública y carecen de razón social ${ }^{33}$. De ahí su denominación de anómalas y su enorme dificultad de localización entre la documentación notarial que silencia el modo de articulación del capital mercantil francés que con más frecuencia se emplea en la práctica mercantil cotidiana ${ }^{34}$.

Estas cuentas en participación, que Jacques Savary llegaba a identificar en 1673 con las sociedades anónimas - según la definición de la época ${ }^{35}$-, son una de las fórmulas asociativas que mejor define la participación francesa en la segunda mitad del Seiscientos en la economía madrileña, similares a los procedimientos de financiación, que operan en otros ámbitos de la vida comercial en la época moderna ${ }^{36}$, y se erigen para los mercaderes de lonja franceses en un insustituible instrumento de participación comercial al asegurar unas mayores oportunidades de beneficios con un menor índice de riesgo. Asimismo, son acuerdos que resultan muy significativos desde el punto de vista de los mecanismos de la ascensión económica y social. Con este pano-

32 En efecto, las cuentas en participación en su modalidad «encomienda, mercancias y cambios" constituye ei fundamento del afianzamiento de los negocios franceses en la Corte: Ver ZYLBERBERG, M., Une centre financier (...), p. 273.

33 Bernal, A.M. y Garcia BaQuero, A. Tres siglos del comercio sevillano (1598-1868), Cuestiones y problemas. Sevilla, 1976.

34 Definido s por PETIT, C. La compañia mercantil (...), p. 58. En otros estudios se recogen datos sobre esto sistemas de información: FRANCH BENAVENT, R. Crecimiento comercial (...), pp. 275 y 280; Carrasco, G. Los instrumentos (...), pp. 78-79.

35 SavarY, J. Le parfait negociante (...). Cap. XXIII, p. 156. Citado en PETIT, C. La compañia mercantil (...), p. 58 y nota 11.

36 Vilar, P. La Catalogne (...). Franch Benavent, R. Crecimiento comercial (...). pp.286 y ss. Carrasco, G. Los instrumentos (...), pp. 71 y ss. 
rama la burguesía mercantil francesa en Madrid aprovecha esa coyuntura difícil, ya que el riesgo de confiscaciones y prohibiciones, así como la naturaleza socioeconómica de esta inmigración, favorece que los franceses que se establecieron en la Corte no tengan una actividad específica ${ }^{37}$.

Bien al contrario, su campo de actuación es tan amplio como el de los comerciantes madrileños. Joyerías como la de los Baraduque, lencerías como la de Tomás de Arteaga, roperías como las de los Astorgue y los Broquel y mercerías como las de Magdalena Marcha, invierten su dinero en la comercialización de productos tanto al detall como al por mayor. Pero también pueden asociarse con mercaderes madrileños o con otros franceses para tras unos años especializados en el comercio al por menor dar el gran salto al gran comercio. Al final, la empresa gala en Madrid aparece como una compañía defectiva, es decir, que no ha llegado a su estado de madurez pero que, se pone al servicio de las grandes compañías de distribución y servicios europeas. Todavía las actuaciones económicas del mercader francés son el recurso más eficaz para el conocimiento del pleno rendimiento al que llega la estructura organizativa más elemental hasta que la compañia mercantil adquiera toda su relevancia en la centuria siguiente ${ }^{38}$. Mientras tanto la compañía de compra y venta de mercancías al detall pasa a dedicarse al negocio al por mayor y desde allí diversifica sus operaciones al negocio de los créditos y los cambios.

En cuanto a su plan contable que, correspondiendo al de su época, está diseñado con criterio analítico, simple ${ }^{39}$ y flexible, en la mayoría de las ocasiones, se localiza en las cuentas de las diferentes "empresas" que aparecen recogidas entre legajos de papeles sueltos que el mercader de lonja acumula en los locales de su lonja-almacen y se reduce a procedimientos que dan primacía analítica al cliente-corresponsal donde se recogen las comisiones cobradas por ellas. Con ello,

37 La misma naturaleza económica se desprende de otros estudios sobre el capital comercial francés: GiRALT, E., "La colonia mercantii (...), pp. 217 y ss. Asimismo, en Zaragoza: Gómez Zorraquino, J.l. Zaragoza y el capital comercial. Zaragoza, 1987, pp. 39-43.

38 ZYLBERBERG, M. Si une douce domination. Les milieux de áffaires français et L'Espag ne vers 1780-180. París, 1983; CHAMBOREDON, R., «Une societe de commerce languedocienne a Cadix: Simon et Arnal Fornier et Cia (Novembre 1768 - Mars 1786). La burguesia de negocios en la Andalucia de la llustración. II, pp. 35-53.

39 Archivo General de Simancas (A.G.S.), Guerra Antigua (G.A.), Leg. 3534, Consulta de 1 de junio de 1671. 
se adecua a la dualidad tamaño-complejidad del negocio. Las cuentas recogidas en folios sueltos ${ }^{40}$ supone la ausencia notable de una contabilidad, mostrando un diseño donde las cuentas básicas no se encuentran definidas. Se trata de un sistema contable eficaz que cubre unas necesidades más especulativas que comerciales ${ }^{41}$.

Asimismo, el municipio siempre tuvo una relación directa con la empresa gremial, no sólo en el ámbito de la producción sino también en el de la distribución. La empresa francesa, como lonja abierta, se desarrolla y evoluciona en el marco de las rígidas normativas del gremio de la Especiería de la calle de las Postas y Portal de Santa cruz, al que se encuentran adscritos algunos comerciantes franceses.

En efecto, el mercader de lonja francés trafica con mercancías pertenecientes a la renta de la Especiería. La declaración de don Manuel Calderón así lo atestigua, quien muestra el registro de dos partidas pertenecientes a la renta de la Especería: "Santo Domingo en 10 de julio 960 millares de alfileres pequeños, y 140 gruesas de sortijas de hueso; y 160 docenas de manillas de lo mismo; y 260 docenas dijo gruesas de botones de cerda (...)". "Santo Domingo, en 15 de agosto 27 marcos de rosarios de ambares y el dicho Manuel Calderon dijo que ademas de las dichas partidas tenía otras tres que no estaban sentadas en el libro y tenía en su poder papeles del dicho Juan Barranquet y que se obligaba a la paga de los derechos de dichas mercaderías, los cuales exhibió ante el escribano."

No obstante, por el fuerte carácter comercial que tenían los negocios de estos mercaderes, estaban gravados con los impuestos propios de la comercialización, bien en el trato al por menor (alcabala y cuatro por ciento) bien en la venta al por mayor o en almacen (la alcaba al viento cobrada en las audanas de la villa en concepto de producto que entra en Madrid): "Vega en uno de octubre pagará a la alcabala y cuatro por ciento de lo que vendiere de tres mil pieles de conejos de media arroba, su fecha en Madrid a dos de octubre de 1673. Juan Barranquet (...)» "Santo Domingo en 5 de octubre pagare la alcabala y cuatro por ciento de lo que se vendiere de 948 millares de alfileres (...)", "Santo Domingo,

40 Que nosotros no hemos podido consultar pero que así se describen en los registros realizados por las autoridades de la epoca a las tiendas lonjas: ver A.G.S., Contaduría del Sueldo (C.S.)., 2. a época, Leg. 149, 7 de enero de 1674 y en A.G.S., G.A., Leg. 3534, consulta de 1 de junio de 1671.

41 A.H.P.M., P. 10.107, 31 de agosto de 1679, sin foliar. 
en dos de Noviembre pagare a la alcabala y cuatro por ciento de lo que se vendiere de 17 libras de rosarios de ámbares que me han enviado en una cajita de San Sebastián. Madrid y Noviembre a 3 de $1673^{42}$ ”.

En cuanto a la actividad económica de las compañías, que comporta otro de los elementos esenciales para el conocimiento de su naturaleza, no sólo nos habla de una especialización en sentido estricto, sino también de un punto de partida que conduce, desde los negocios puramente mercantiles, a la configuración de una empresa de servicios que abarca operaciones financieras de muy diverso tipo. Además, después de esta caracterización el análisis de las actuaciones comerciales de estos mercaderes en Madrid se convierte en el recurso más eficaz para el conocimiento del pleno rendimiento al que llega la estructura empresarial resultante.

Las empresas francesas y, en particular, las de los mercaderes analizados, prestan su infraestructura para la práctica del comercio a la gruesa pero también a los cambios y al depósito bancario, convirtiéndose en una empresa especializada en la circulación de bienes y servicios que llega hasta las finanzas estatales donde acude al reclamo de asentistas y arrendadores de rentas, como Bernardino Garimundi, en quienes depositan sus ahorros para la obtención de fáciles y rápidas ganancias sin los riesgos que implica la práctica comercial. La fuerte demanda de estos productos convertía su consumo en unas actividades lucrativas. Los negocios de estos mercaderes franceses especializados en el comercio internacional se reactivaba con inyecciones de capital procedentes de una acumulación primitiva de capital comercial o de préstamos del círculo mercantil al que pertenecian, cuando no de la conjunción de ambos.

Por tanto, la imagen válida, en términos generales, de que la ocupación del espacio comercial por los comerciantes franceses de todas aquellas escalas de la comercialización dentro de una red de intercambios que, naciendo en Madrid, alcanza primero su hinterland local y regional en la primera mitad del siglo XVII, para extenderse más tarde al espacio comercial castellano (lanero, sobre todo), y finalmente incluso, a algunas plazas mercantiles marítimas dentro de la península, se había completado en la primera mitad del siglo XVII. Fuera del ám-

42 A.G.S., C.S., Leg. 149, 19 de enero de 1674. 
bito local y de los mercados y ferias regionales, tres eran los circuitos de intercambios hacia los que orientaban sus preferencias los franceses de Madrid: los puertos altánticos como los mercados castellanos del interior peninsular y, en menor medida, el litoral mediterráneo. De los primeros se servían para dar salida a los productos castellanos y extremeños - la lana, sobre todo- y para recibir los que desde su tierra de origen y las regiones levantinas les remitían fabricantes y comerciantes franceses, así como los provenientes del comercio colonial; de los segundos eran meros intermediarios financieros al servicio de intereses - genoveses y portugueses- que no disponían de unas redes principales en los circuitos atlánticos. Esto les permitía, según se advierte en las minuciosas relaciones de productos que incorporan a los inventarios, tener bien y puntualmente surtidos sus estantes y trastiendas de toda clase de tejidos y ultramarinos.

Las redes cambiarias de la empresa Casanova se cruzan en algún momento con las de Juan de la Tapié y Pascual del Campo, que participan de los intereses de la firma Vignaux y cía, pues Juan Casanova tiene un papel también destacado en el mecanismo de comercialización internacional, que vendría, pues, a multiplicar la complejidad comercial de la modesta organización empresarial francesa en la segunda mitad del Seiscientos. Por otra parte, las redes comerciales y financieras que comunican tanto con la fachada atlántica como la mediterránea y los territorios interiores mantuvieron siempre una gran continuidad en los tratos del Madrid del Seiscientos, destacando Francia, Flandes ${ }^{43}$ y otros territorios satélites fronterizos al Imperio Alemán, aunque es presumible que también, tras Wetsfalia, las Provincias Unidas tuvieran un cierto protagonismo ${ }^{44}$.

Por último, con estas características, las compañías francesas ocupan progresivamente un espacio específico en el comercio madrileño: el de las redes y circuitos que fluyen desde Madrid a Bayona, conectando con aquellas que llegan hasta Thiers, París y Lyon. De los primeros se servían para dar salida a los productos castellanos - la lana, sobre todo- y para recibir los que desde su tierra de origen y las regiones levantinas les remitían fabricantes y comerciantes franceses, así como los provenientes del mercado local, regional y, en ocasiones, colonial.

43 Ramos Medina, M. ${ }^{a}$ D., «Mercaderes flamencos (...), pp. 238-249.

44 Ramos Medina, M. ${ }^{a}$ D., Una familia (...). Ibid. 
Algunos comerciantes galos analizados contituyen un gozne que integra dos espacios comerciales: por una parte, el Mediterráneo, que a través de genoveses, milaneses y algunos loreneses con intereses en el comercio centroeuropeo sitúan sus intereses en manos de mercaderes como Pierre Catalán o Guillermo Vignaux. Con todo, el comerciante madrileño posee ya en la segunda mitad del siglo xVII una red mercantil propia, extendida desde los puertos del Atlántico y del mediterráneo, gaditanos y alicantinos, así como unas importantes relaciones con agentes comerciales que tienen poderes de representación, en aduanas y puertos secos en el interior peninsular.

\section{CONCLUSIONES}

Aunque lo expuesto hasta ahora no agota el tema sino que, bien al contrario, abre el camino a nuevas investigaciones sobre la empresa mercantil en el Madrid de los Austrias desde la perspectiva del análisis microecómico y la funcionalidad de sus redes comerciales y financieras, algunas conclusiones cabe destacar. En primer lugar, los mercaderes de lonja franceses, por una parte, invierten en el comercio internacional madrileño y al igual que el sector más activo del comercio extranjero se introduce en los sectores más avanzados del comercio y la banca internacional; por otra, brindan un cuadro de actitudes de la burguesía mercantil gala instalada en Madrid que constatan la universal similitud en las conductas del perfecto negociante francés reconocible en su preferencia por la empresa familiar, la diversificación de sus operaciones, la colaboración con sus connacionales o el afán de reconocimiento.

Además, si queremos profundizar más, hallamos otro rasgo coincidente en el hecho de que por vez primera la burguesía francesa se ha colocado en cierta medida a la vanguardia de las iniciativa comerciales en la Corte, adquiere clara conciencia de su propia potencialidad y, sobre todo, de haber completado un ciclo dentro de la trayectoria que comenzó a desarrollarse a finales del siglo xvı. En este sentido, en la primera mitad del siglo XVII, una vez consolidadas las anteriores conquistas y poseyendo los medios necesarios, es decir, experiencia y capitales, no detendrán su paso, sino que abordan la siguiente etapa con mayor ambición cuando las circunstancia políticas lo permiten, buscando mientras tanto nuevas vias, canalizando recursos hacia una serie de mayores proyectos dotados de mayor originalidad y ambición. 
En segundo lugar, este paseo por las estructuras y la funcionalidad de las empresas de comercio francesas analizadas nos ha dado a conocer el funcionamiento cotidiano de los mecanismos que permiten la insercción del capital francés dentro de los circuitos mercantiles castellanos y europeos. Asimismo, la reconstrucción de la empresa mercantil gala, no sobre la base de sus contabilidades, que es la vía normal en esta clase de trabajos, sino a través de una fragmentaria documentación notarial, que es la única disponible, pero que exige un esfuerzo sobrehumano de lectura y exégesis para rellenar los huecos, completar las operaciones, adivinar los movimientos, nos ha permitido conocer el modo más frecuente de articular el capital comercial y financiero, los convenios asociativos o cuentas en participación, descubriendo los orígenes de la funcionalidad de la empresa extranjera en Madrid a finales del Seiscientos en los niveles más modestos de la negociación y la lógica actuación de aquellos comerciantes madrileños que hacian fortuna al resguardo de la demanda de la Corte. Además, la firma del Tratado de los Pirineos, desde un punto de vista microeconómico, supuso no sólo el punto culminante de las realizaciones de aquella primera generación de franceses que comienza a actuar en Madrid entre 1634 y 1646, sino también el auge de unos intercambios que exigió la puesta a punto de un sistema sencillo que atendiera las complejas necesidades del capital comercial en rápido crecimiento.

Por otra parte, la madurez alcanzada por los intercambios en manos de estos comerciantes demuestra que tienen el sentimiento de pisar los umbrales de una época de objetivos más amplios, impulsando el nacimiento de unidades empresariales de diferente consideración económica. Además, en 1659 la colonia francesa reune las condiciones económicas (disponibilidad de capitales, existencia de una burguesía mercantil integrada en las estructuras de la Villa y Corte y con suficiente capacidad emprendedora) y políticas para un aprovechamiento intenso tanto de la fluidez lograda en los contactos con el mundo europeo tras varias décadas de experiencias, como de las oportunidades brindadas por un amplio mercado cortesano en un momento de expansión de la demanda.

Asimismo, los negocios mercantiles analizados responden a la verdadera naturaleza comercial y financiera, localizando el eslabón perdido de la empresa mercantil en los niveles más elementales de la negociación. Pero aunque no podemos hablar de dominación francesa en el comercio castellano que nos ha permitido descubrir los orígenes de aquellas casas 
de comercio y banca que actúan en Madrid, una centuria después en el entorno de la Puerta del Sol, participando activamente en las principales iniciativas financieras setecentistas al amparo de Madrid como centro financiero peninsular, un proceso que culmina con la fundación del Banco de San Carlos en 1782, al final, la empresa gala en Madrid aparece como una compañía defectiva que no ha llegado a su estado de madurez pero que, se pone al servicio de las grandes compañías de distribución y servicios europeas más evolucionadas de la época.

Finalmente, la geografía de las relaciones de estos mercados nos descubre una fuerte presencia extranjera en el comercio internacional que más allá de mantener una relación económica firmemente apoyada en la adscripción nacional pues, bajo la óptica de la vida cotidiana en los negocios, la endogamia socioprofesional se imbrica con el ejercicio continuado de las actividades mercantiles, descubrimos que existen unas relaciones económicas específicas interesantes pues aunque entre éstos y aquellos existieron a lo largo del Seiscientos importantes diferencias de naturaleza económica y social, gran parte de las actuaciones de los comerciantes galos en Madrid se realizan en nombre de casas comerciales extranjeras con intereses en el comercio madrileño. 